\title{
Bowel diversion should be used with caution in stenosing anal Crohn's disease
}

\author{
M E R Williamson, L E Hughes
}

\begin{abstract}
Proximal diversion has commonly been used for severe perianal Crohn's disease in an attempt to relieve local symptoms, whether the primary intestinal disease is in the colon or small bowel. Two patients are presented in whom diversion led to severe symptomatic disease in the previously normal defunctioned bowel. In each case the development of colonic disease was associated with increasing anal stenosis leading to retention of purulent fluid within the bowel lumen. Faecal stream diversion should be used with caution in stenosing anal Crohn's disease.
\end{abstract}

(Gut 1994; 35: 1139-1140)

Perianal complications occur in up to $30 \%$ of patients with Crohn's disease, ${ }^{1}$ and indeed, may be the mode of presentation. ${ }^{2}$ The anal manifestations can be divided into primary and secondary lesions. Primary lesions are a direct result of the Crohn's disease process, and include, in increasing order of severity; fissures, ulcerated piles, cavitating ulcers, and aggressive ulceration. Secondary lesions are the mechanical complications of the primary lesions, and often occur after the Crohn's disease itself has become inactive. They include skin tags, abscesses and fistulae, and stricture formation. ${ }^{34}$

It has been recognised for some time that faecal diversion in the treatment of perianal Crohn's disease may not only fail to achieve regression of the anal disease, ${ }^{5}$ but that the act of diversion itself may result in a non-specific inflammation of the previously normal defunctioned bowel. ${ }^{67}$

We report our experience of a similar phenomenon, where diversion led to severe Crohn's disease. We urge caution when considering a defunctioning stoma in the longterm treatment of perianal complications of Crohn's disease.

The cases reported on draw attention to the fact that this process is possibly exacerbated if stenosis develops in the diseased anus.

Department of Surgery, University of Wales College of Medicine, Cardiff M E R Williamson L E Hughes

Correspondence to: Professor L E Hughes, Department of Surgery, University of Wales College of Medicine, Heath Park, Cardiff, South Glamorgan CF4 4XN.

Accepted for publication 23 November 1993

\section{Case history 1}

A 16 year old boy, with a history of mid small bowel Crohn's disease since the age of 3 years, was referred for advice on the treatment of his severe perianal disease. He had had a defunctioning loop ileostomy five years previously in an attempt to cure his recurrent perianal abscess and fistula formation. After diversion, he suffered escalating symptoms culminating in continuous extreme perianal pain and purulent discharge.

On examination, his development was that of an 8 year old, weighing only $30 \mathrm{~kg}$, despite longterm treatment with enteral nutrition and growth hormone supplements. Examination under anaesthesia showed circumferential ulceration of the perianal skin and anal canal and, loss of mucosa of the lower $5 \mathrm{~cm}$ of rectum. Relief of spasm and gentle anal dilatation resulted in discharge of over one litre of pus from the colon.

At subsequent laparotomy the whole colon was macroscopically diseased and a panproctocolectomy was performed, together with a limited small bowel resection. Gross examination of the opened operative specimen showed numerous ulcers throughout the colon, the rectum was thickened and ulcerated, with the lower $6 \mathrm{~cm}$ and the anal canal showing total ulceration with mucosal replacement by granulation tissue. Histological examination confirmed the changes as resulting from Crohn's disease with unusually florid granulomatous inflammation.

After proctocolectomy, pain and toxic symptoms resolved. The patient is growing rapidly in height, weight, and development without further growth hormone or nutritional supplements.

\section{Case history 2}

A 45 year old man, with a 10 year history of Crohn's disease, was referred for further management of troublesome anal complications. From the original diagnosis to the time of presentation he had had 21 surgical procedures for recurrent sepsis. Five years previously a defunctioning sigmoid loop colostomy was performed in an attempt to cure the anal disease. Perianal abscess and fistula formation, however, continued to occur with similar frequency, and he developed ankylosing spondylitis.

Examination under anaesthesia showed a superficial fistula between the anus and scrotum, within the anal canal there was an old cavitating ulcer in the midline posteriorly and a chronic fissure anteriorly. There was a tight stenosis immediately above the anorectal gross inflammation of the rectal mucosa with oedema and cobble stoning. The colon proximal to the colostomy was normal on colonoscopy. Biopsy specimens of the transverse colon and splenic flexure were histologically normal, those from the 
descending colon showed mild Crohn's disease.

Proctosigmoidectomy was performed, with the formation of a permanent left iliac fossa colostomy. The opened operative specimen showed a second stenosis just distal to the colostomy in addition to the terminal rectal stenosis. The bowel between the two strictures was grossly ulcerated but the macroscopic disease stopped abruptly at the proximal stricture. Histological examination showed transmural inflammation with focal perforation resulting from a severe idiopathic inflammatory bowel disease, consistent with Crohn's disease.

The perineal wound healed without incident. At current follow up (21 months after operation) the patient remains well. $\mathrm{He}$ has no perineal symptoms and has no recrudescence of small or large bowel Crohn's disease. His arthropathy has not changed after surgery.

\section{Discussion}

The two patients presented had suffered severe anal Crohn's disease over many years. Proximal diversion did not alleviate the symptomatic perianal disease in either case. Conversely subsequent increasing anal stenosis seemed to contribute to the development of a very severe 'closed loop' exacerbation of the Crohn's disease distal to the diversion, with increased severity of bowel symptoms in both cases and gross systemic toxicity in one. In both cases rectal excision had been advised against on the basis that the extent of ulceration and fibrosis would endanger urogenital organs.

Crohn's disease in the colon had not been recorded in either patient before defunctioning, so it seems probable that the development of the anorectal stenosis had a role in determining the severity of the subsequent bowel involvement. This is supported by the fact that severe disease stopped abruptly at the ileocaecal valve in case 1 and the sigmoid stenosis in case 2 . The proximal diversion obscured the symptomatic effects of increasing anal stenosis, so that the significance of this development in exacerbating the disease was not appreciated. Furthermore, the constant leakage of pus from the anus in case 1 seemed to contribute to the exceptional severity of the anorectal ulceration.

In response to the reported benefits of bowel 'rest' by faecal diversion in the treatment of Crohn's disease, Burman et $a l{ }^{7}$ presented a series of 29 patients in which this was performed. Although the overall health of the patients was improved, in only two cases did the treatment result in 'healing' of Crohn's colitis and permit another successful anastomosis. In the 15 colons that were removed there was macroscopic and histological disease present despite faecal diversion. Coincidental perianal disease had not been helped by the procedure and in fact four patients had developed anal complications while defunctioned. ${ }^{7}$

Glotzer et $a l,{ }^{5}$ reported the phenomenon of 'diversion colitis' in patients who had had faecal stream diversion for a variety of noninflammatory bowel disease conditions. The colitis resembled mild ulcerative colitis histologically, without granuloma or other evidence suggesting Crohn's disease. It lasted as long as eight years with persisting diversion, but both macroscopic and microscopic appearances returned to normal after restoration of the faecal stream. In their discussion they went on to report a similar phenomenon in patients with Crohn's disease and similarly the changes were reversed after re-anastomosis, other authors have confirmed these findings. ${ }^{6}$ The aetiology remains a mystery, one theory centres upon the presence of bacterial pathogens; another is based upon a lack of nutrients resulting from faecal stream diversion, recently there have been reports of improving the changes by the introduction of short chain fatty acids, although the most recent controlled trial has failed to confirm this. ${ }^{8}$ Our cases were different in that severe Crohn's disease was found rather than a nonspecific diversion colitis.

In conclusion, faecal stream diversion is not a simple option when treating anal Crohn's disease. In many patients perianal Crohn's lesions do not contribute greatly to morbidity. ${ }^{9}$ In severely symptomatic patients where local medical or surgical procedures do not control symptoms, rectal excision is a more certain method of relieving symptoms. If proximal diversion is used, and symptoms persist, development of anal stenosis as an exacerbating factor should be considered.

1 Homan WP, Tang C-K, Thorbjarnarson B. Anal lesions complicating Crohn's disease. Arch Surg 1976; 111: 1333-5.

2 Keddie N. Anorectal manifestations of inflammatory bowel disease. Br f Hosp Med 1980; 24: 294-7.

3 Hughes LE. Surgical pathology and management of anorectal Crohn's disease. $\mathcal{F} R$ Soc Med 1978; 71: 644-51.

4 Hughes LE, Taylor BA. Perianal lesions in Crohn's disease. In: Inflammatory bowel disease. 2nd Ed. London: Churchill Livingstone, 1990.

5 Glotzer DJ, Glick ME, Goldman H. Proctitis and colitis following diversion of the fecal stream. Gastroenterology 1980; 80: 438-41.

6 Korelitz BI, Cheskin LJ, Sohn N, Sommers SC. Proctitis after fecal diversion in Crohn's and its elimination with reanastomosis: implications for surgical management. Gastroenterology 1984; 87: 710-3.

7 Burman JH, Thompson H, Cooke WT, Alexander-Williams J. The effect of diversion of intestinal contents on the
progress of Crohn's disease of the large bowel. Gut 1971; progress

8 Guillemot F, Colombel JF, Neut C, et al. Treatment of diversion colitis by short-chain fatty acids. Dis Colon Rectum 1991; 34: 861-4.

9 Buchmann P, Keighley MRB, Allan RN, Thompson $\mathrm{H}$, Alexander-Williams J. Natural history of perianal Crohn's disease. Ten year follow-up: a plea for conservatism Am $\mathcal{F}$ Surg 1980; 140: 642-40. 